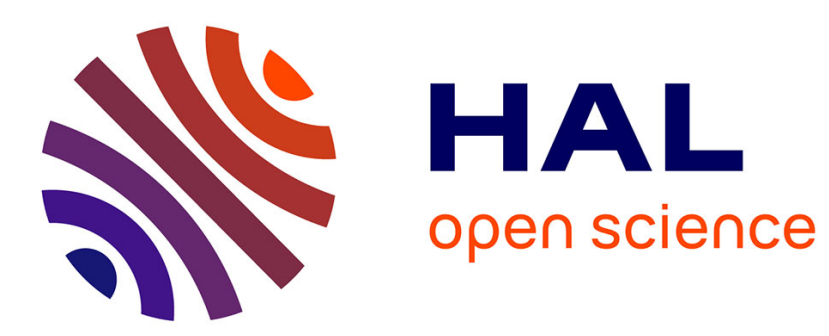

\title{
Identical, similar or different? is a single brain model sufficient?
}

Michel Thiebaut de Schotten, Tim Shallice

\section{To cite this version:}

Michel Thiebaut de Schotten, Tim Shallice. Identical, similar or different? is a single brain model sufficient?. Cortex, 2016, 10.1016/j.cortex.2016.12.002 . hal-01419604

\section{HAL Id: hal-01419604 \\ https://hal.sorbonne-universite.fr/hal-01419604}

Submitted on 21 Dec 2016

HAL is a multi-disciplinary open access archive for the deposit and dissemination of scientific research documents, whether they are published or not. The documents may come from teaching and research institutions in France or abroad, or from public or private research centers.
L'archive ouverte pluridisciplinaire HAL, est destinée au dépôt et à la diffusion de documents scientifiques de niveau recherche, publiés ou non, émanant des établissements d'enseignement et de recherche français ou étrangers, des laboratoires publics ou privés. 


\section{Identical, similar or different? is a single brain model sufficient?}

Michel Thiebaut de Schotten ${ }^{1-3^{*}}$ and Tim Shallice ${ }^{4,5^{*}}$

${ }^{1}$ Brain Connectivity and Behaviour Group, Frontlab, Brain and Spine Institute, Paris France.

${ }^{2}$ Sorbonne Universités, UPMC Univ Paris 06, Inserm, CNRS, Institut du cerveau et la moelle (ICM) - Hôpital Pitié-Salpêtrière, Boulevard de l'hôpital, F-75013, Paris, France

${ }^{3}$ Centre de Neuroimagerie de Recherche CENIR, Groupe Hospitalier PitiéSalpêtrière, Paris, France

${ }^{4}$ Institute of Cognitive Neuroscience, University College, London, UK

${ }^{5}$ Cognitive Neuroscience Sector, International School for Advanced Studies SISSA-ISAS, Trieste, Italy

${ }^{*}$ Corresponding author:

Michel Thiebaut de Schotten, Brain Connectivity and Behaviour Group, La Salpêtrière, 47 Boulevard de l'Hôpital, 75013 Paris, France.

Email address: michel.thiebaut@gmail.com

Tim Shallice, Cognitive Neuroscience Sector, Scuola Internazionale Superiore di Studi Avanzati (S.I.S.S.A.), Via Beirut, 2-4, 34014 Trieste TS, Italy. Tel.: +39 040 3787610; fax: +39040 3787615 .

Email address: shallice@sissa.it 


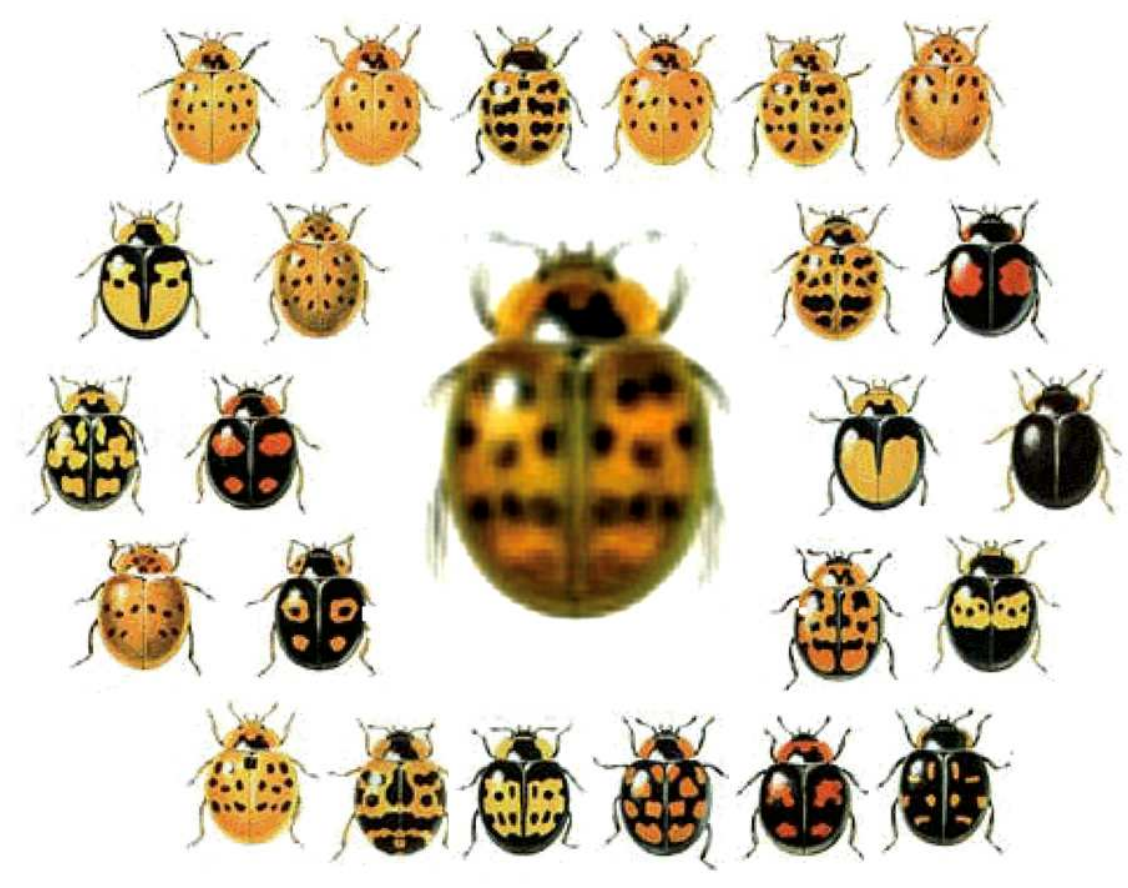

Figure 1: Harlequin ladybirds' variants (as defined here http://www.harlequinsurvey.org). The ladybird in the centre is an average image of all other ladybirds. This average image shares most of the main individual characteristics but is lacking important features specific to subgroups. The ladybirds used here are a metaphor for the human brain variability in anatomy and function.

To make progress in the empirical investigation of the functioning of the mind and how it relates to underlying brain structures standardly entailed making several assumptions. In particular, approaches as different as a cognitive neuroscience tool like functional magnetic resonance imaging ( $(\mathrm{MMRI})$, as most typically used, and single-case neuropsychology have this in common: when drawing theoretical inferences, they assume that individuals within a culture share a similar or an equivalent organisation of their cognitive functions, and presumably have the same underlying brain anatomy (Caramazza, 1986; Goldin et al., 2008; Greene et al., 2004; Johnson-Frey, 2004)

However large population studies as well as the advent of neuroimaging have been marked by the discovery of significant inter-individual variability in cognitive function and brain anatomy. These individual differences include purely qualitative or categorical ones and ones where differences lie on at least interval scales. With 
respect to categorical differences, classically in cognitive psychology, it was known that children could adopt either spatial (Huttenlocher, 1968) or verbal (Clark, 1969) strategies in solving so-called three-term series problems (Ormrod, 1979). There are now many analogous examples. Thus individuals can adopt different strategies, such as spatial, motor or piecemeal for carrying out mental rotation (Khooshabeh et al., 2013; Kosslyn et al., 1998; Tomasino \& Rumiati, 2004). Turning to anatomy, the white matter connections, sulci and cytoarchitecture may differ across individuals. For instance, in $90 \%$ of the population, the left cortico-spinal tract decussates more dorsally than the right corticospinal tract (Yakovlev \& Rakic, 1966). Despite its apparent close similarity with the distribution of handedness, it was latter shown by Kertesz and Geschwind (1971) that this anatomical difference did not predict manual preference. However, Geschwind and Letvitsky (1968) also observed that the planum temporale is larger in the left hemisphere in two thirds of the population, the right being larger in only 11 percent and interpreted this result as an indicator of left hemispheric dominance for language. Hence, while a single model of functional and structural organisation is usually assumed in classical neuropsychological and neuroanatomical models, advanced investigation leads to the obvious observation of a large variability across participants and brains.

Categorical differences can lead to a Pandora's Box of possibilities. Differences across individuals in strategies involve the use of different types of informationprocessing procedures. However, these may or may not be based on differences in the functional organisation of the processing system across the individuals carrying out the strategies; any given strategy may merely reflect the choice of control process, task-set or thought schema on one particular occasion. Moreover, even when underlying on-line mechanisms do differ across individuals, it may be only a small minority that are discrepant. Thus, in a study of functional connectivity of brain regions underlying reading, Heim et al (2009) found that 12/14 subjects fitted one underlying model well with only two individuals being discrepant. We will call such a situation minority-discrepant, and contrast it with major-discrepancy.

Other differences can be more purely quantitative reflecting distributions along gradients of performance and potentially of anatomy. Multimodal distributions, which ultimately collapse into categorical distinctions, and unimodal distributions, which can 
be used for dimensional approaches (i.e. correlations with other dimensions), both exist. For instance, the former (i.e. a multimodal distribution) exists in the discrimination of major minor musical modes (Chubb et al., 2013) in which a bimodal distribution occurs such that $30 \%$ of the population have a close to perfect performance whereas the rest of the $70 \%$ perform around chance. Likewise, the measure of language lateralisation with $\mathrm{AMRI}$ indicate that the hemispheric dominance for language follows a multimodal distribution with most participants having strongly left lateralised activations (about 70\%), with subgroups being respectively slightly left lateralised (about $20 \%$ ), symmetrical (about 10\%) or rightlateralised (less than 1\% and occurring in left-handers only) (Mazoyer et al., 2014). The latter (i.e. a unimodal distribution) seems to be observed in many cognitive tests with no ceiling effects (i.e. Posner paradigm, Posner, 1980) or in the high variability of the distribution of cytoarchitectural fields across the brain (Amunts et al., 2000; Amunts et al., 1999).

How frequently across processes, differences in brain organisation produce differences in functional or cognitive organisation, is still a debated question. In particular, the assumption of a relationship between the size of a brain structure and a participant's performance has echoes of the phrenologists' principle. So, caution needs to be taken before generalising some these interesting findings to the whole functioning of the brain. Thus, statistical correlations between performance on psychometric tests and the size of primary visual areas (Kanai \& Rees, 2011; Schwarzkopf et al., 2011) have been shown. However, a relationship between size and performance should not be taken for granted for all other brain areas. Similarly, the relationship between functional hemispheric lateralisation and anatomical hemispheric asymmetry has recently been extended to the visuospatial domain (Thiebaut de Schotten et al., 2011), but cannot be generalised to all functional lateralisation since symmetrical structures can also support different functions (Concha et al., 2012; Herve et al., 2013). Fortunately, from recent methodological breakthroughs, it would appear that a good match exists between the functional specialisation of brain areas and the pattern of anatomical connections serving these regions at the individual level (Tavor et al., 2016; Thiebaut de Schotten et al., 2016). Interestingly, areas defined by their connectivity exhibit variations in extent and localisation between brains but retain quite a robust pattern of connectivity. Hence, 
these methods might be a new ideal way to study the relationship between structural and functional variability by providing more individually tailored brain models.

These new considerations have potentially major consequences for the theoretical interpretation of single case, case series and group studies. If categorical differences over some cognitive process exist in a population, the single case approach popular in cognitive neuropsychology becomes inferentially somewhat unreliable on this issue, as phenomena found in any one individual will not be generalizable to the whole population (see Shallice, 2015 and in this issue Bartolomeo et al., 2016). However, if this is so, case series and typical group studies, which mix or average behaviours over different types of individuals, can also produce misleading theoretical inferences (Badecker \& Caramazza, 1985; Shallice, 2015). This issue may not be too serious a problem for minority-discrepant situations, but it would be for major-discrepancy ones. By contrast quantitative differences without categorical ones enrich our range of methodologies for understanding the functioning of the brain. Thus, as the papers in this issue demonstrate, one can pinpoint brain areas dedicated to function by exploring the relationship between the volume of brain areas and the corresponding cognitive performance (Bendetowicz et al., 2016), provide evidence on the underlying cognitive mechanisms by quantifying correlations between the performance of tests across individuals (Friedman \& Miyake, 2016) or investigate how aging can modify the cognitive strategies employed to understand others (Klindt et al., 2016).

This means that it becomes critical to investigate individual differences in many situations. Advanced strategies to address the problem produced by categorical differences would be, for instance, to run classifiers such as K-mean clustering (Steinhaus, 1957), principal component analysis (Hotelling, 1933), independent component analysis (Comon, 1994) or non-negative matrix factorisation (Lee \& Seung, 1999) on large populations in order to reduce the risks of flattening differences and so draw stronger conclusions tailored to each category of healthy controls or patient populations. Using this approach, Cerliani et al. (2016) revealed that healthy controls can use different networks of functional activation to perform the same task, Halai et al. (2016) identified the main functional and anatomical components underlying deficits following stroke and Sanefugi et al. (2016) 
discovered separate brain mechanisms supporting different dimensions of ADHD.

Therefore, this Cortex special issue is devoted to the investigation of cognitive and brain variability. After a comprehensive review of the subject matter (Bartolomeo et al., 2016), the first part of this issue highlights individual differences in behaviour and their relationship with differences in underlying functionalist models (Friedman \& Miyake, 2016; Klindt et al., 2016). The second part investigates whether such differences are linked to observable signs in the brain (Bendetowicz et al., 2016; Cazzoli \& Chechlacz, 2016; Cerliani et al., 2016; Mongelli et al., 2016). The final part is devoted to the impact the two first parts should have on neuropsychological methodology (Halai et al., 2016), diagnosis, treatment (Sanefuji et al., 2016) and prognosis (Duffau, 2016; Tzourio-Mazoyer et al., 2016).

It is our hope that this special issue will capture the imagination of the reader and lead to the incorporation of the inter-individual variability dimension into the next generation of cognitive and brain models.

\section{ACKNOWLEDGEMENTS}

This work was supported by the 'Agence Nationale de la Recherche' [grants number ANR-10-IAIHU-06 and number ANR-13-JSV4-0001-01].

\section{REFERENCES}

Amunts, K., Malikovic, A., Mohlberg, H., Schormann, T., \& Zilles, K. (2000). Brodmann's areas 17 and 18 brought into stereotaxic space-where and how variable? Neurolmage, 11(1), 66-84. doi: 10.1006/nimg.1999.0516

Amunts, K., Schleicher, A., Bürgel, U., Mohlberg, H., Uylings, H. B., \& Zilles, K. (1999). Broca's region revisited: cytoarchitecture and intersubject variability. J. Comp. Neurol., 412(2), 319-341.

Badecker, W., \& Caramazza, A. (1985). On consideration of method and theory governing the use of clinical categories in neuroliguistics and cognitive neuropsychology: The case against agrammatism. Cognition, 20, 97-125.

Bartolomeo, P., Seidel-Malkinson, T., \& De Vito, S. (2016). Botallo's error, or the quandaries of the universality assumption. (this issue). 
Bendetowicz, D., Urbanski, M., Aichelburg, C., Levy, R., \& Volle, E. (2016). Brain morphometry predicts individual creative potential and the ability to combine remote ideas. Cortex(this issue).

Caramazza, A. (1986). On drawing inferences about the structure of normal cognitive systems from the analysis of patterns of impaired performance: the case for singlepatient studies. Brain Cogn, 5(1), 41-66.

Cazzoli, D., \& Chechlacz, M. (2016). A matter of hand: Causal links between hand dominance, structural organization of fronto-parietal attention networks, and variability in behavioural responses to transcranial magnetic stimulation. Cortex. doi: 10.1016/j.cortex.2016.06.015

Cerliani, L., Aquino, D., Contarino, v., \& Bizzi, A. (2016). Disentangling subgroups of participants recruiting shared as well as different brain regions for the execution of the verb generation task: a data-driven $\mathrm{fMRI}$ study. Cortex(this issue).

Chubb, C., Dickson, C. A., Dean, T., Fagan, C., Mann, D. S., Wright, C. E., . . Kowalsky, E. (2013). Bimodal distribution of performance in discriminating major/minor modes. $J$ Acoust Soc Am, 134(4), 3067-3078. doi: 10.1121/1.4816546

Clark, H. H. (1969). Linguistic processes in deductive reasoning. Psychol Rev, 76, 387-404.

Comon, P. (1994). Independent Component Analysis: a new concept? , 36(3), 287-314

Concha, M. L., Bianco, I. H., \& Wilson, S. W. (2012). Encoding asymmetry within neural circuits. Nat Rev Neurosci, 13(12), 832-843. doi: 10.1038/nrn3371

Duffau, H. (2016). A two-level model of interindividual anatomo-functional variability of the brain and its implications for neurosurgery. Cortex. doi: 10.1016/j.cortex.2015.12.009

Friedman, N. P., \& Miyake, A. (2016). Unity and diversity of executive functions: Individual differences as a window on cognitive structure. Cortex(this issue). doi: 10.1016/j.cortex.2016.04.023

Geschwind, N., \& Levitsky, W. (1968). Human brain: left-right asymmetries in temporal speech region. Science, 161(837), 186-187.

Goldin, P. R., McRae, K., Ramel, W., \& Gross, J. J. (2008). The neural bases of emotion regulation: reappraisal and suppression of negative emotion. Biol Psychiatry, 63(6), 577-586. doi: 10.1016/j.biopsych.2007.05.031

Greene, J. D., Nystrom, L. E., Engell, A. D., Darley, J. M., \& Cohen, J. D. (2004). The neural bases of cognitive conflict and control in moral judgment. Neuron, 44(2), 389-400. doi: 10.1016/j.neuron.2004.09.027

Halai, A. D., Woollams, A. M., \& Lambon Ralph, M. A. (2016). Using principal component analysis to capture individual differences within a unified neuropsychological model of chronic post-stroke aphasia: Revealing the unique neural correlates of speech fluency, phonology and semantics. Cortex. doi: 10.1016/j.cortex.2016.04.016

Heim, S., Eickhoff, S. B., Ischebeck, A. K., Frederich, A. D., Stephan, K. E., \& Amunts, K. (2009). Effective connectivity of the left BA 44, BA 45 and inferior temporal gyrus during lexical and phonological decisions identified with DCM. Hum Brain Mapp, 30(2), 392-402.

Herve, P. Y., Zago, L., Petit, L., Mazoyer, B., \& Tzourio-Mazoyer, N. (2013). Revisiting human hemispheric specialization with neuroimaging. Trends Cogn Sci, 17(2), 69-80. doi: 10.1016/j.tics.2012.12.004

Hotelling, H. (1933). Analysis of a complex of statistical variables into principal components. Journal of Educational Psychology, 24, 417-441. 
Huttenlocher, J. (1968). Constructing spatial images: a strategy in reasoning. Psychol Rev, $75,550-560$.

Johnson-Frey, S. H. (2004). The neural bases of complex tool use in humans. Trends Cogn Sci, 8(2), 71-78. doi: 10.1016/j.tics.2003.12.002

Kanai, R., \& Rees, G. (2011). The structural basis of inter-individual differences in human behaviour and cognition. Nat Rev Neurosci, 12(4), 231-242. doi: 10.1038/nrn3000

Kertesz, A., \& Geschwind, N. (1971). Patterns of pyramidal decussation and their relationship to handedness. Arch Neurol, 24(4), 326-332.

Khooshabeh, P., Hegarty, M., \& Shipley, T. F. (2013). Individual differences in mental rotation: piecemeal versus holistic processing. Exp Psychol, 60(3), 164-171. doi: 10.1027/1618-3169/a000184

Klindt, D., Devaine, M., \& Daunizeau, J. (2016). Does the way we read others' mind change over the lifespan? Insights from a massive web poll of cognitive skills from childhood to late adulthood. Cortex(this issue).

Kosslyn, S. M., DiGirolamo, G. J., Thompson, W. L., \& Alpert, N. M. (1998). Mental rotation of objects versus hands: neural mechanisms revealed by positron emission tomography. Psychophysiology, 35(2), 151-161.

Lee, D. D., \& Seung, H. S. (1999). Learning the parts of objects by non-negative matrix factorization. Nature, 401(6755), 788-791. doi: 10.1038/44565

Mazoyer, B., Zago, L., Jobard, G., Crivello, F., Joliot, M., Perchey, G., . . Tzourio-Mazoyer, N. (2014). Gaussian mixture modeling of hemispheric lateralization for language in a large sample of healthy individuals balanced for handedness. PLoS One, 9(6), e101165. doi: 10.1371/journal.pone.0101165

Mongelli, V., Dehaene, S., Vinckier, F., Peretz, I., Bartolomeo, P., \& Cohen, L. (2016). Music and words in the visual cortex: The impact of musical expertise. Cortex. doi: 10.1016/j.cortex.2016.05.016

Ormrod, J. E. (1979). Cognitive processes in the solution of three-term series problems. Am J Psychol, 92(2), 235-255.

Posner, M. I. (1980). Orienting of attention. Q J Exp Psychol, 32(1), 3-25.

Sanefuji, M., Craig, M., Parlatini, V., Mehta, M. A., Murphy, D. G., Catani, M., ... Thiebaut de Schotten, M. (2016). Double-dissociation between the mechanism leading to impulsivity and inattention in Attention Deficit Hyperactivity Disorder: A restingstate functional connectivity study. Cortex. doi: 10.1016/j.cortex.2016.06.005

Schwarzkopf, D. S., Song, C., \& Rees, G. (2011). The surface area of human V1 predicts the subjective experience of object size. Nat Neurosci, 14(1), 28-30. doi: $10.1038 / \mathrm{nn} .2706$

Shallice, T. (2015). Cognitive neuropsychology and its vicissitudes: The fate of Caramazza's axioms. Cogn Neuropsychol, 32(7-8), 385-411. doi: 10.1080/02643294.2015.1131677

Steinhaus, H. (1957). Sur la division des corps matériels en parties. Bull. Acad. Polon. Sci., 4(12), 801-804.

Tavor, I., Parker Jones, O., Mars, R. B., Smith, S. M., Behrens, T. E., \& Jbabdi, S. (2016). Taskfree MRI predicts individual differences in brain activity during task performance. Science, 352(6282), 216-220. doi: 10.1126/science.aad8127

Thiebaut de Schotten, M., Dell'Acqua, F., Forkel, S. J., Simmons, A., Vergani, F., Murphy, D. G., \& Catani, M. (2011). A lateralized brain network for visuospatial attention. Nat Neurosci, 14(10), 1245-1246. doi: 10.1038/nn.2905 
Thiebaut de Schotten, M., Urbanski, M., Batrancourt, B., Levy, R., Dubois, B., Cerliani, L., \& Volle, E. (2016). Rostro-caudal Architecture of the Frontal Lobes in Humans. Cereb Cortex. doi: 10.1093/cercor/bhw215

Tomasino, B., \& Rumiati, R. I. (2004). Effects of strategies on mental rotation and hemispheric lateralization: neuropsychological evidence. J Cogn Neurosci, 16(5), 878888. doi: 10.1162/089892904970753

Tzourio-Mazoyer, N., Perrone-Bertolotti, M., Jobard, G., Mazoyer, B., \& Baciu, M. (2016). Multi-factorial modulation of hemispheric specialization and plasticity for language in healthy and pathological conditions: A review. Cortex. doi: 10.1016/j.cortex.2016.05.013

Yakovlev, P. J., \& Rakic, P. (1966). Pattern of decussation of bulbar pyramids and distribution of pyramidal tracts on two sides of the spinal cord. Trans Amer Neurol Assoc, 91, 366-367. 